\title{
Low-dose aspirin use and survival in colorectal cancer: results from a population-based cohort study
}

\author{
Ronan T. Gray ${ }^{1 *}$, Helen G. Coleman ${ }^{1}$, Carmel Hughes², Liam J. Murray ${ }^{1}$ and Chris R. Cardwell ${ }^{1}$
}

\begin{abstract}
Background: Aspirin has been proposed as a novel adjuvant agent in colorectal cancer (CRC). Six observational studies have reported CRC-specific survival outcomes in patients using aspirin after CRC diagnosis but the results from these studies have been conflicting. Using a population-based cohort design this study aimed to assess if low-dose aspirin use after diagnosis reduced CRC-specific mortality.

Methods: A cohort of 8391 patients with Dukes' A-C CRC (2009-2012) was identified from the Scottish Cancer Registry and linked to national prescribing and death records. Adjusted hazard ratios (HRs) and 95\% confidence intervals (Cls) for CRC-specific mortality were calculated using time-dependent Cox regression.

Results: There were 1064 CRC-specific deaths after a median follow-up of 3.6 years. Post-diagnostic low-dose aspirin use was not associated with a reduction in CRC-specific mortality either before or after adjustment for confounders (adjusted $\mathrm{HR}=1.17,95 \% \mathrm{Cl} 1.00-1.36$ ). In sensitivity analysis pre-diagnostic low-dose aspirin was also not associated with reduced CRC-specific mortality (adjusted HR $=0.96,95 \% \mathrm{Cl} 0.88-1.05$ ).

Conclusion: Low-dose aspirin use, either before or after diagnosis, did not prolong survival in this population-based CRC cohort.
\end{abstract}

Keywords: Aspirin, Colorectal cancer, Survival, Pharmaco-epidemiology

\section{Background}

Numerous observational studies and long term followup of randomised trials (of aspirin for cardiovascular indications) suggest that aspirin use is associated with a reduced risk of colorectal neoplasia [1]. Clinical trails have also confirmed that aspirin can reduce the risk of developing recurrent adenomatous polyps [2] in the general population and incident colorectal cancer (CRC) in Lynch syndrome carriers [3]. More recently, further evidence from long-term follow-up of these cardiovascular trials suggests aspirin could reduce metastases in CRC patients and therefore could have utility in CRC treatment [4]. To date, six epidemiological studies [5-10] have investigated the association between aspirin use after diagnosis and CRC-specific mortality. However,

\footnotetext{
* Correspondence: rgray05@qub.ac.uk

'Cancer Epidemiology and Health Services Research Group, Centre for Public Health, Queen's University Belfast, Royal Victoria Hospital, Belfast, Northern Ireland BT12 6BA, UK

Full list of author information is available at the end of the article
}

these studies reached different conclusions (two observed no association $[5,6]$ whilst four observed marked reductions [7-10]), and had various limitations including small sample size, [6] restriction to subgroups, [6] the potential for biased estimates (described later) [7, 8] and self-reported exposure ascertainment [9]. Although additional studies have investigated post-diagnostic aspirin use and all-cause mortality in CRC, [11] results of these studies could reflect non-cancer related events. Cancerspecific mortality limits events to those related to the cancer and represents a more specific endpoint for evaluating the efficacy of an adjuvant therapy [12].

Additional studies assessing aspirin use after diagnosis and CRC survival are therefore warranted to investigate the potential role of adjuvant aspirin treatment in CRC. We therefore investigated whether post-diagnostic aspirin use was associated with improved CRC-specific mortality in a Scottish population-based CRC cohort. 


\section{Methods}

\section{Data source}

The study utilised linkages between national datasets from Scotland including the Scottish Cancer Registry (SMR06), the Prescribing Information System (available from January 2009 to January 2015), the General/Acute Inpatient and Day Case dataset (SMR01), the Outpatient Attendance dataset (SMR00) and the National Records of Scotland Death Records. Linkages between data sources were conducted using the Community Health Index number (unique to individuals in Scotland). The Privacy Advisory Committee of the National Health Service (NHS) National Services Scotland (NSS) approved the study.

\section{Study population}

A cohort of newly diagnosed Dukes' A-C CRC patients was identified within the Scottish Cancer Registry (ICD codes of the colon $\mathrm{C} 18$ or rectum C20 including the recto-sigmoid junction C19) between January 2009 and December 2012. Cohort members with previous cancer diagnoses (after January 1999), apart from in situ neoplasms and non-melanoma skin cancers, were excluded (Fig. 1). Deaths were identified from National Records of Scotland with coverage up to 1st January 2015 (or from Scottish Cancer Registry death records) with CRCspecific deaths defined as those with underlying cause of death ICD code C18, C19, C20, C21 (anus) or C26 (other and ill-defined digestive organs). Deaths in the

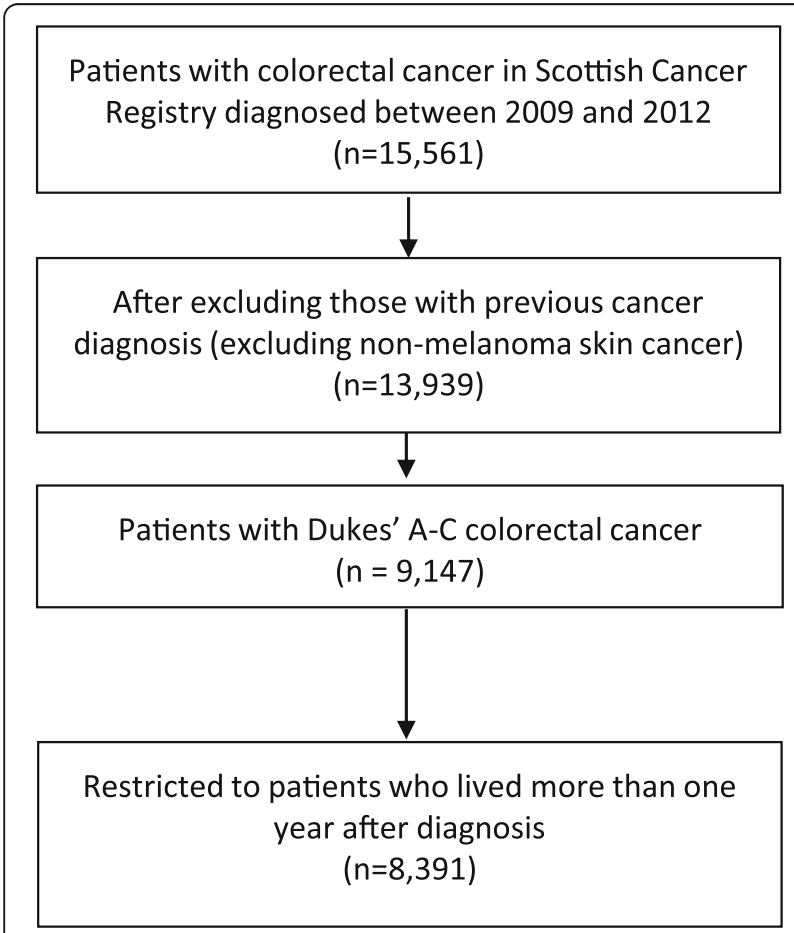

Fig. 1 Patient selection for analysis in cohort study first year after CRC diagnosis were removed, this restriction reduces the likelihood of including patients who were not recurrence-free at exposure [13]. Patients were therefore followed up from 1 year after CRC diagnosis to death, the date they left Scotland or 1st January 2015.

\section{Exposure data}

The Prescribing Information System (available from January 2009 to January 2015) holds all medicines dispensed in the community in Scotland [14]. Low-dose (75 mg) aspirin exposure was identified from dispensing records within this database. A quantity of 28 tablets was assumed for the less than $0.1 \%$ of prescriptions where quantity was assumed incorrect. Daily defined doses (DDD) were calculated based on the quantity of tablets as defined by the World Health Organisation [15]. Aspirin use was investigated as a time-varying covariate (patients were initially considered non-users and then users after a lag of 6 months after their first aspirin prescription) [13, 16]. This lag ensured new prescriptions in the six-month period prior to death were not considered as they may reflect end of life treatment. Dose (exposure)-response analyses were conducted with individuals considered non-users prior to 6 months after first use (i.e. aspirin users were considered non-users until the lag period passed), a short term user between 6 months after first use and 6 months after the 12th prescription (i.e. up to 1 year of exposure after the lag period) and a longer term user after this time (users for more than 1 year after the lag period).

\section{Covariates}

Data available from the Scottish Cancer Registry included Dukes' stage, histological grade and surgery, chemotherapy and radiotherapy in the 6 months after diagnosis. Comorbidities that contribute to the Charlson index were determined prior to diagnosis based upon ICD10 diagnosis codes, as described previously, [17] in Scottish hospital inpatient (SMR01) and outpatient data (SMR00). The SMR01 dataset contains information on hospital diagnoses and operations and the SMR00 dataset (both available from January 1999 to January 2015) contains diagnosis and procedures from new and follow up appointments at outpatient clinics. A deprivation measure was determined using the 2009 Scottish Index of Multiple Deprivation based upon postcode of residence [18].

\section{Statistical analysis}

Time-dependent Cox regression models were used to calculate hazard ratios (HRs) for CRC-specific death and 95\% confidence intervals (CIs) for aspirin users compared with non-users as described previously [19]. Multivariable analyses adjusted for the potential confounders 
age, sex, year of diagnosis, deprivation, site (colon or rectum), stage, grade, cancer treatment within 6 months (radiotherapy, chemotherapy, surgery), comorbidities (prior to diagnosis, including acute myocardial infarction, congestive heart failure, peripheral vascular disease, cerebral vascular accident, pulmonary disease, peptic ulcer, liver disease, diabetes, renal disease) and statin use (as a time-varying covariate). Analyses were conducted by number of tablets and repeated for all-cause mortality. Subgroup analyses were conducted by site (colon or rectal) and pre-diagnostic aspirin use (de novo versus pre- and post-diagnostic aspirin use).

Sensitivity analysis was conducted by increasing the lag period (the time from first dispensed aspirin prescription to when the patient started to accrue aspirin exposure follow-up time) to 1 year. A simplified analysis was also performed using Cox regression to assess survival in aspirin users compared to non-users in the first year after colorectal cancer diagnosis in individuals living more than 1 year after diagnosis (follow-up commenced 1 year from the date of diagnosis until the date of last data collection); this controls for immortal time bias without requiring time-varying covariates [20]. Finally, an analysis was conducted based upon aspirin prescriptions in the year prior to diagnosis (excluding patients diagnosed in 2009 for whom a full year of prescription records prior to diagnosis may not be available), not excluding deaths in the first year after diagnosis and including all colorectal cancer patients regardless of Dukes' stage. The adjusted model for pre-diagnostic aspirin use did not include stage, grade or cancer treatment to avoid over adjustment [21, 22] as they could be on the causal pathway for the association between prediagnostic aspirin use and CRC-specific mortality.

An adjusted post-hoc analysis was undertaken comparing cardiovascular deaths between post-diagnostic aspirin users and non-users. Cardiovascular deaths were those in which the underlying death was ICD 10 codes I0-99, G45, Q20-26, F01 or equivalent ICD-9 codes. The adjusted model for this analysis was similar to the primary multivariable analysis except only non-cardiovascular comorbidities (pulmonary disease, peptic ulcer, liver disease, diabetes, renal disease) were included. All statistical analyses were conducted in STATA 13 software (StataCorp, College Station, TX).

\section{Results}

A total of 8391 incident Dukes' A to C CRC cases met the inclusion criteria (Fig. 1), in which there was on average 3.6 years of follow-up after diagnosis (median $=3.6$, range1-6 years). Patient characteristics by aspirin use are shown in Table 1. Aspirin users in the year after diagnosis were more likely to be older, male and reside in more deprived areas. Stage and grade were generally similar by aspirin use, but a smaller proportion of aspirin users compared to non-users had Dukes' $\mathrm{C}$ disease (post-diagnostic use, $32.7 \%$ versus $35.5 \%$ respectively). Aspirin users were also more likely to have comorbidities (particularly cardiovascular disease and diabetes) and use statins but a smaller proportion received adjuvant chemotherapy.

Post-diagnostic aspirin use was not associated with reduced CRC-specific mortality after adjustment for potential confounders (HR $=1.17,95 \%$ CI 1.00-1.36) (Table 2). Results for overall survival were similar, except that the observed increases in mortality were detected as statistically significant after adjustment (adjusted HR $=1.21$ 95\%CI 1.07-1.37). Post-hoc analysis confirmed there was a marked increase in cardiovascular deaths in postdiagnostic aspirin users compared to non-users (adjusted $\mathrm{HR}=1.63$, 95\% CI 1.15-2.29).

There was no evidence of an exposure response when users consuming more (long term users) or less (short term users) than a 365-day supply were compared with non-users (Table 2). Stratifying by tumour location did not greatly alter the size or direction of the association for CRC-specific mortality (adjusted $\mathrm{HR}=1.13,95 \% \mathrm{CI}$ 0.94-1.36 versus adjusted $\mathrm{HR}=1.26,95 \%$ CI $0.94-1.69$ in colon and rectal cancer patients respectively).

The results of the planned sensitivity analyses are documented in Tables 3 and 4. Repeating the analysis using a simplified one-year analysis did not demonstrate a survival benefit for post-diagnostic aspirin use. Interestingly cancer-specific and overall survival were markedly worse in de novo post-diagnostic aspirin users (adjusted CRCspecific survival HR $=1.51,95 \%$ CI 1.12-2.05; adjusted overall survival $\mathrm{HR}=1.53,95 \% \mathrm{CI} 1.19-1.95)$ when post-diagnostic aspirin use versus non-use was stratified by pre-diagnostic aspirin use. However, when aspirin use was compared to non-use in the year prior to diagnosis, there was no association with CRC-specific (adjusted $\mathrm{HR}=0.96,95 \% \mathrm{CI} 0.88-1.05)$ or overall survival (adjusted HR $=0.99,95 \%$ CI 0.92-1.06). Finally, the results of the main time-varying analysis of post-diagnostic aspirin use were not greatly altered when the lag period was increased from 6 to 12 months (adjusted cancerspecific survival $H R=1.08,95 \% C I$ 0.94-1.26; adjusted overall survival $H R=1.15,95 \%$ CI 1.03 to 1.29 ).

\section{Discussion}

Low-dose aspirin use after colorectal cancer diagnosis was not associated with improved CRC-specific survival in this large Scottish population-based cohort study. Specifically, low-dose aspirin use was associated with a $17 \%$ increase in CRC-specific mortality, but this was not statistically significant and did not follow an exposure response. Overall, in subgroup and sensitivity analyses the findings of the main analyses were relatively consistent. 
Table 1 Characteristics of colorectal cancer patients by post-diagnostic aspirin use

\begin{tabular}{|c|c|c|c|c|}
\hline & \multicolumn{4}{|c|}{$\begin{array}{l}\text { Aspirin use in first year after cancer } \\
\text { diagnosis }^{a}\end{array}$} \\
\hline & \multicolumn{2}{|c|}{ Yes $(n=2150)$} & \multicolumn{2}{|c|}{ No $(n=6241)$} \\
\hline & Number & $\%$ & Number & $\%$ \\
\hline \multicolumn{5}{|l|}{ Age } \\
\hline$<50$ & 13 & 0.6 & 432 & 6.9 \\
\hline $50-59$ & 131 & 6.1 & 1113 & 17.8 \\
\hline $60-69$ & 586 & 27.3 & 1973 & 31.6 \\
\hline 70-79 & 934 & 43.4 & 1876 & 30.1 \\
\hline$\geq 80$ & 486 & 22.6 & 847 & 13.6 \\
\hline \multicolumn{5}{|l|}{ Gender } \\
\hline Men & 1387 & 64.5 & 3287 & 52.7 \\
\hline \multicolumn{5}{|l|}{ Deprivation (fifth) } \\
\hline 1 (most deprived) & 447 & 20.8 & 1039 & 16.6 \\
\hline 2 & 497 & 23.1 & 1272 & 20.4 \\
\hline 3 & 429 & 20.0 & 1263 & 20.2 \\
\hline 4 & 412 & 19.2 & 1361 & 21.8 \\
\hline 5 (least deprived) & 365 & 17.0 & 1305 & 20.9 \\
\hline \multicolumn{5}{|l|}{ Tumour location } \\
\hline Colon & 1493 & 69.4 & 4227 & 67.7 \\
\hline Rectum/rectosigmoid junction & 657 & 30.6 & 2014 & 32.3 \\
\hline \multicolumn{5}{|l|}{ Dukes' stage } \\
\hline$A$ & 597 & 27.8 & 1683 & 27.0 \\
\hline B & 851 & 39.6 & 2340 & 37.5 \\
\hline C & 702 & 32.7 & 2218 & 35.5 \\
\hline \multicolumn{5}{|l|}{ Grade } \\
\hline Well differentiated & 82 & 3.8 & 203 & 3.3 \\
\hline Moderately differentiated & 1646 & 76.6 & 4796 & 76.8 \\
\hline Poorly differentiated & 315 & 14.7 & 968 & 15.5 \\
\hline Missing & 107 & 5.0 & 274 & 4.4 \\
\hline \multicolumn{5}{|l|}{ Treatment (within six months) } \\
\hline Surgery & 2020 & 94.0 & 5908 & 94.7 \\
\hline Radiotherapy & 192 & 8.9 & 679 & 10.9 \\
\hline Chemotherapy & 472 & 22.0 & 2167 & 34.7 \\
\hline \multicolumn{5}{|l|}{ Comorbidity before cancer diagnosis } \\
\hline Acute myocardial infarction & 300 & 14.0 & 103 & 1.7 \\
\hline Congestive heart failure & 135 & 6.3 & 94 & 1.5 \\
\hline Peripheral vascular disease & 145 & 6.7 & 80 & 1.3 \\
\hline Cerebral vascular accident & 162 & 7.5 & 141 & 2.3 \\
\hline Pulmonary disease & 207 & 9.6 & 383 & 6.1 \\
\hline Peptic ulcer & 59 & 2.7 & 151 & 2.4 \\
\hline
\end{tabular}

Table 1 Characteristics of colorectal cancer patients by post-diagnostic aspirin use (Continued)

\begin{tabular}{|c|c|c|c|c|}
\hline & \multicolumn{4}{|c|}{$\begin{array}{l}\text { Aspirin use in first year after cancer } \\
\text { diagnosis }^{a}\end{array}$} \\
\hline & \multicolumn{2}{|c|}{ Yes $(n=2150)$} & \multicolumn{2}{|c|}{ No $(n=6241)$} \\
\hline & Number & $\%$ & Number & $\%$ \\
\hline Liver disease & 6 & 0.3 & 25 & 0.4 \\
\hline Diabetes & 290 & 13.5 & 285 & 4.6 \\
\hline Renal disease & 87 & 4.0 & 102 & 1.6 \\
\hline Statin use after diagnosis & 1647 & 76.6 & 1490 & 23.9 \\
\hline
\end{tabular}

Six observational studies have reported the association between CRC-specific outcomes and post-diagnostic aspirin use in CRC [5-10]. The findings from the present study add further inconsistency to the evidence base therefore the differences between the studies should be discussed. These findings are within the confidence intervals for the null association our research group previously reported using linked data from the Clinical Practice Research Datalink and the English National Cancer Data Repository $(n=4794$, adjusted CRCspecific survival HR $=0.99,95 \%$ CI 0.86-1.15) [5]. Kothari et al. also reported a null association between $\mathrm{CRC}$-specific mortality and low-dose aspirin use at CRC diagnosis, but the study was small and limited to tumours that were PIK3CA mutant $(n=185)$ [6].

Notably, our current results do contrast with the inverse association reported by McCowan et al. (2013) in a separate regional Scottish population-based study [8]. Important differences in the statistical analysis could explain these findings. In particular, their analysis used an unlagged start/stop time-varying covariate. This potentially introduces bias through reverse causation as deaths were allocated to the exposed/unexposed group on the basis of whether the aspirin prescription covered the death date $[5,23]$. In particular, prescription medications may be stopped as patients enter the terminal phase of their disease [24]. Failure to include a lag period can therefore over estimate any association or inadvertently make it appear that aspirin use is associated with a reduced risk of disease progression due to misclassification.

Similarly, Goh et al. (2014) reported a $62 \%$ reduction $(\mathrm{HR}=0.38,95 \%$ CI $0.17-0.84)$ in CRC-specific mortality among $n=726$ post-diagnostic aspirin users utilising a national prescription database [7]. However the authors do not describe any method to eliminate immortal time bias (such as use of a time-varying covariate) which could artificially create a protective effect [16]. It is also worth noting that our study only assessed low-dose aspirin use, therefore we could not investigate the improved outcomes for predominantly high-dose aspirin users observed in previous studies [9]. Finally, despite 
Table 2 Association between aspirin use after diagnosis and CRC-specific and overall survival in patients with colorectal cancer

\begin{tabular}{|c|c|c|c|c|c|c|c|}
\hline & Mortality & Patients & Person years & $\begin{array}{l}\text { Unadjusted HR } \\
(95 \% \mathrm{Cl})\end{array}$ & $P$ value & $\begin{array}{l}\text { Adjusted }^{\mathrm{a}} \mathrm{HR} \\
(95 \% \mathrm{Cl})\end{array}$ & $P$ value \\
\hline \multicolumn{8}{|l|}{ CRC-specific survival } \\
\hline Aspirin non-user & 729 & 5881 & 15,957 & 1.00 (ref. cat.) & & 1.00 (ref. cat.) & \\
\hline Aspirin user & 335 & 2510 & 6178 & $1.22(1.07,1.39)$ & 0.003 & $1.17(1.00,1.36)$ & 0.06 \\
\hline 1 to 365 DDDs vs. non-user & 160 & 725 & 2549 & $1.34(1.12,1.59)$ & 0.001 & $1.23(1.02,1.50)$ & 0.03 \\
\hline$\geq 365$ DDDs vs. non-user & 175 & 1785 & 3629 & $1.12(0.95,1.33)$ & 0.18 & $1.10(0.90,1.33)$ & 0.36 \\
\hline \multicolumn{8}{|l|}{ Overall survival } \\
\hline Aspirin non-user & 1035 & 5881 & 15,957 & 1.00 (ref. cat.) & & 1.00 (ref. cat.) & \\
\hline Aspirin user & 600 & 2510 & 6178 & $1.51(1.37,1.67)$ & $<0.001$ & $1.21(1.07,1.37)$ & 0.002 \\
\hline 1 to 365 DDDs vs. non-user & 263 & 725 & 2549 & $1.59(1.39,1.83)$ & $<0.001$ & $1.26(1.08,1.46)$ & 0.004 \\
\hline$\geq 365$ DDDs vs. non-user & 337 & 1785 & 3629 & $1.45(1.28,1.65)$ & $<0.001$ & $1.18(1.02,1.37)$ & 0.03 \\
\hline
\end{tabular}

Abbreviations: $\mathrm{Cl}$ confidence interval, $C R C$ colorectal cancer, $D D D$ daily defined dose, $H R$ hazard ratio

${ }^{a}$ Multivariable model contains age, sex, year of diagnosis, deprivation, site (colon or rectum), stage, grade, cancer treatment within 6 months (radiotherapy, chemotherapy, surgery), comorbidities (prior to diagnosis, including acute myocardial infarction, congestive heart failure, peripheral vascular disease, cerebral vascular accident, pulmonary disease, peptic ulcer, liver disease, diabetes, renal disease) and statin use (as a time-varying covariate)

using broadly similar methodology in large populationbased CRC cohorts, the results of the current study conflict with the modest protective association (adjusted $\mathrm{HR}=0.8595 \% \mathrm{CI} 0.79,0.92)$ observed with three or more aspirin prescriptions reported by Bains et al. [10]. It is unclear why the results of these studies differ but some of this could reflect differences in the confounding variables that were included in multivariable analyses; in particular, only the current study adjusted for chemotherapy or radiotherapy use, the presence of comorbid illnesses and deprivation.

The 20\% increase in all-cause mortality in aspirin users compared to non-users in this colorectal cancer cohort warrants further discussion but as post hoc analysis demonstrated that this increase was driven by cardiovascular mortality, it seems likely that confounding by indication is responsible. Residual confounding may also bias the CRCspecific analyses reported in this study. In particular, the

Table 3 Sensitivity analyses for the association between aspirin use and CRC-specific survival in patients with colorectal cancer

\begin{tabular}{|c|c|c|c|c|c|c|c|c|c|c|}
\hline & \multicolumn{3}{|c|}{ Aspirin user } & \multicolumn{3}{|c|}{ Aspirin non-user } & \multirow[b]{2}{*}{$\begin{array}{l}\text { Unadjusted HR } \\
(95 \% \mathrm{Cl})\end{array}$} & \multirow[b]{2}{*}{$P$ value } & \multirow[b]{2}{*}{$\begin{array}{l}\text { Adjusted HR } \\
(95 \% \mathrm{Cl})\end{array}$} & \multirow[b]{2}{*}{$P$ value } \\
\hline & Mortality & Patients & Person years & Mortality & Patients & Person years & & & & \\
\hline \multicolumn{11}{|l|}{ CRC-specific survival } \\
\hline \multicolumn{11}{|c|}{ Post-diagnostic aspirin use (fixed time exposure in first year) ${ }^{a}$} \\
\hline $\begin{array}{l}\text { Aspirin user vs. } \\
\text { non-user }\end{array}$ & 310 & 2150 & 5692 & 754 & 6241 & 16,442 & $1.19(1.05,1.36)$ & 0.01 & $1.10(0.94,1.29)$ & 0.22 \\
\hline \multicolumn{11}{|c|}{ Post-diagnostic aspirin use versus non-use stratified by pre-diagnostic use (excludes 2009 cases) ${ }^{b}$} \\
\hline Pre-diagnostic users & 168 & 1333 & 2983 & 46 & 257 & 614 & $0.75(0.54,1.04)$ & 0.08 & $0.80(0.56,1.13)$ & 0.20 \\
\hline $\begin{array}{l}\text { Pre-diagnostic } \\
\text { non-users }\end{array}$ & 51 & 435 & 744 & 467 & 4301 & 9930 & $1.52(1.13,2.03)$ & 0.01 & $1.51(1.12,2.05)$ & 0.01 \\
\hline \multicolumn{11}{|c|}{ Aspirin use vs. non-use in year before colorectal cancer diagnosis (excludes 2009 cases) ${ }^{c}$} \\
\hline $\begin{array}{l}\text { Aspirin user vs. } \\
\text { non-user }\end{array}$ & 1104 & 2853 & 6460 & 2551 & 7555 & 18,652 & $1.23(1.14,1.32)$ & $<0.001$ & $0.96(0.88,1.05)$ & 0.37 \\
\hline \multicolumn{11}{|c|}{$\begin{array}{l}\text { Abbreviations: } C l \text { confidence interval, } C R C \text { colorectal cancer, } H R \text { hazard ratio } \\
\text { a'Model contains age, sex, year of diagnosis, deprivation, site (colon or rectum), stage, grade, cancer treatment within six months (radiotherapy, chemotherapy, } \\
\text { surgery), comorbidities (prior to diagnosis, including acute myocardial infarction, congestive heart failure, peripheral vascular disease, cerebral vascular accident, } \\
\text { pulmonary disease, peptic ulcer, liver disease, diabetes, renal disease) and statin use (in first year after diagnosis) } \\
\text { bexcluding patients diagnosed in } 2009 \text { (who do not have complete prescription records for year before diagnosis). Based upon main time-varying covariate } \\
\text { multivariable model containing age, sex, year of diagnosis, deprivation, site (colon or rectum), stage, grade, cancer treatment within } 6 \text { months (radiotherapy, } \\
\text { chemotherapy, surgery), comorbidities (prior to diagnosis, including acute myocardial infarction, congestive heart failure, peripheral vascular disease, cerebral } \\
\text { vascular accident, pulmonary disease, peptic ulcer, liver disease, diabetes, renal disease) and statin use (as time-varying covariate) } \\
\text { 'Excluding patients diagnosed in } 2009 \text { (who do not have complete prescription records for year before diagnosis) but not excluding patients who die within } \\
1 \text { year of diagnosis; adjusted model contains age, sex, year of diagnosis, deprivation, site (colon or rectum), comorbidities (prior to diagnosis, including acute } \\
\text { myocardial infarction, congestive heart failure, peripheral vascular disease, cerebral vascular accident, pulmonary disease, peptic ulcer, liver disease, diabetes, renal } \\
\text { disease) and statin use (in year prior to diagnosis) }\end{array}$} \\
\hline
\end{tabular}


Table 4 Sensitivity analyses for the association between aspirin use and overall survival in patients with colorectal cancer

\begin{tabular}{|c|c|c|c|c|c|c|c|c|c|c|}
\hline & \multicolumn{3}{|c|}{ Aspirin user } & \multicolumn{3}{|c|}{ Aspirin non-user } & \multirow[b]{2}{*}{$\begin{array}{l}\text { Unadjusted HR } \\
(95 \% \mathrm{Cl})\end{array}$} & \multirow[b]{2}{*}{$P$ value } & \multirow[b]{2}{*}{$\begin{array}{l}\text { Adjusted HR } \\
(95 \% \mathrm{Cl})\end{array}$} & \multirow[b]{2}{*}{$P$ value } \\
\hline & Mortality & Patients & $\begin{array}{l}\text { Person } \\
\text { years }\end{array}$ & Mortality & Patients & $\begin{array}{l}\text { Person } \\
\text { years }\end{array}$ & & & & \\
\hline \multicolumn{11}{|l|}{ Overall survival } \\
\hline \multicolumn{11}{|c|}{ Post-diagnostic aspirin use (fixed time exposure in first year) $)^{a}$} \\
\hline Aspirin user vs. non-user & 554 & 2150 & 5692 & 1081 & 6241 & 16,442 & $1.48(1.33,1.64)$ & $<0.001$ & $1.17(1.03,1.32)$ & 0.01 \\
\hline \multicolumn{11}{|c|}{ Post-diagnostic aspirin use versus non-use stratified by pre-diagnostic use (excludes 2009 cases) ${ }^{b}$} \\
\hline Pre-diagnostic users & 290 & 1333 & 2983 & 70 & 257 & 614 & $0.84(0.65,1.10)$ & 0.21 & $0.88(0.67,1.17)$ & 0.39 \\
\hline $\begin{array}{l}\text { Pre-diagnostic } \\
\text { non-users }\end{array}$ & 84 & 435 & 744 & 638 & 4301 & 9930 & $1.79(1.42,2.25)$ & $<0.001$ & $1.53(1.19,1.95)$ & 0.001 \\
\hline \multicolumn{11}{|c|}{ Aspirin use vs. non-use in year before colorectal cancer diagnosis (excludes 2009 cases) ${ }^{c}$} \\
\hline $\begin{array}{l}\text { Aspirin user vs. } \\
\text { non-user }\end{array}$ & 1506 & 2853 & 6460 & 3117 & 7555 & 18,652 & $1.37(1.29,1.46)$ & $<0.001$ & $0.99(0.92,1.06)$ & 0.77 \\
\hline \multicolumn{11}{|c|}{$\begin{array}{l}\text { Abbreviations: } \mathrm{Cl} \text { confidence interval, } H R \text { hazard ratio } \\
{ }^{\mathrm{a} M o d e l} \text { contains age, sex, year of diagnosis, deprivation, site (colon or rectum), stage, grade, cancer treatment within six months (radiotherapy, chemotherapy, } \\
\text { surgery), comorbidities (prior to diagnosis, including acute myocardial infarction, congestive heart failure, peripheral vascular disease, cerebral vascular accident, } \\
\text { pulmonary disease, peptic ulcer, liver disease, diabetes, renal disease) and statin use (in first year after diagnosis) } \\
{ }^{6} \text { Excluding patients diagnosed in } 2009 \text { (who do not have complete prescription records for year before diagnosis). Based upon main time-varying covariate } \\
\text { multivariable model containing age, sex, year of diagnosis, deprivation, site (colon or rectum), stage, grade, cancer treatment within } 6 \text { months (radiotherapy, } \\
\text { chemotherapy, surgery), comorbidities (prior to diagnosis, including acute myocardial infarction, congestive heart failure, peripheral vascular disease, cerebral } \\
\text { vascular accident, pulmonary disease, peptic ulcer, liver disease, diabetes, renal disease) and statin use (as time-varying covariate) } \\
\text { 'Excluding patients diagnosed in } 2009 \text { (who do not have complete prescription records for year before diagnosis) but not excluding patients who die within } \\
1 \text { year of diagnosis; adjusted model contains age, sex, year of diagnosis, deprivation, site (colon or rectum), comorbidities (prior to diagnosis, including acute } \\
\text { myocardial infarction, congestive heart failure, peripheral vascular disease, cerebral vascular accident, pulmonary disease, peptic ulcer, liver disease, diabetes, renal } \\
\text { disease) and statin use (in year prior to diagnosis) }\end{array}$} \\
\hline
\end{tabular}

prevalence of cardiovascular disease in Scotland is amongst the highest in Europe and is the highest of all the regions in the UK [25]. Cardiovascular disease is known to be associated with reduced physical activity and obesity, two factors that are independently associated with worse survival outcomes in colorectal cancer [26-28]. Unfortunately it was not possible to adjust for these lifestyle variables in the current cohort. Therefore, as low-dose aspirin is prescribed for the secondary prevention of cardiovascular disease, obesity and physical inactivity may be associated with both the exposure and the outcome of interest.

The strengths of the current study include its size, population-based design and use of dispensing information with detailed information. The contemporary nature of the cohort and its population-based approach also enhance the external validity of the results. One of the main limitations is that as this is an observational study there is the potential for residual confounding. In addition to the absence of information on lifestyle variables, the comorbidity data may not be complete as it relied on hospital records rather than GP recorded diagnoses or patient interviews. Also, while dispensing information is more robust than prescribing information, compliance cannot be confirmed. Over-the-counter usage could also result in some users being misclassified but a previous UK study using GP prescribing data estimated that $70-80 \%$ [29] of aspirin use in the age-group we investigated was prescription-based, while another showed little evidence of misclassification by aspirin usage when compared with patient recall [30]. Cause of death can also be misclassified when relying on data from national statistics records. We were also unable to assess cyclooxygenase 2 (COX-2) expression or PIK3CA mutation status, two potential molecular biomarkers that may predict response to aspirin therapy $[9,31,32]$. Importantly though, while these markers did differentiate tumours more likely to benefit from aspirin use in the these studies, the survival benefit associated with aspirin use also existed before stratification of the cohorts by molecular profile $[9,32]$. Finally, follow-up in the current cohort is relatively short (median $=3.6$ years). However, in a separate Scottish cohort study, McCowan et al. demonstrated a survival benefit associated with aspirin use after a shorter median follow-up of 2.8 years [8].

\section{Conclusion}

In summary, there is inconsistent evidence from previous observational studies on the association between post-diagnostic low-dose aspirin use and improved CRC-specific survival. In the present study we did not find any evidence of a reduction in cancer-specific mortality in aspirin users. Although we observed a small increase in all-cause mortality this seems likely to reflect confounding by indication. For these reasons clinical trials assessing adjuvant aspirin therapy in colorectal cancer (NCT02467582; NCT02301286; NCT00565708; ISRCTN74358648) are keenly anticipated but are not due to report until at least 2022. 


\section{Abbreviations}

Cl: Confidence interval; CRC: Colorectal cancer; DDD: Daily defined dose; HR: Hazard ratio

\section{Acknowledgements}

The authors would like to thank the research coordinators (Lizzie Nicholson and David Bailey) and NHS National Services Scotland for facilitating access and analysis of the Scottish cohort.

\section{Funding}

Queen's University Belfast funded data access. R.T.G. was supported by a Health \& Social Care Research and Development Division of the Public Health Agency (HSC R\&D Division) Doctoral Fellowship. H.G.C. was supported by a Cancer Research UK Population Health Postdoctoral Fellowship. The funding bodies had no input into the design of the study, data collection, data interpretation or the decision to submit the manuscript.

\section{Availability of data and materials}

The datasets supporting the conclusions of this article are accessible to researchers through the electronic Data Research and Innovation Service (eDRIS) (http://www.isdscotland.org/Products-and-Services/EDRIS/).

\section{Authors' contributions}

Study conception and design CH, LJM, CRC. Data analysis and interpretation RTG, HGC, CH, LJM, CRC. Drafting or revising manuscript RTG, HGC, CH, LJM CRC. Final approval for submission RTG, HGC, CH, LJM, CRC. Accountable for all aspects of the work RTG, HGC, CH, LJM, CRC

\section{Ethics approval and consent to participate}

This cohort study used non-identifiable information from routinely collected administrative healthcare datasets in Scotland and had approval from the NHS National Services Scotland Privacy Advisory committee (ref: PAC 36/14).

\section{Consent for publication}

Approval to use anonymous routinely collected patient data has been obtained as described above.

\section{Competing interests}

The authors declare that they have no competing interests.

\section{Publisher's Note}

Springer Nature remains neutral with regard to jurisdictional claims in published maps and institutional affiliations.

\section{Author details}

${ }^{1}$ Cancer Epidemiology and Health Services Research Group, Centre for Public Health, Queen's University Belfast, Royal Victoria Hospital, Belfast, Northern Ireland BT12 6BA, UK. ${ }^{2}$ School of Pharmacy, Queen's University Belfast, 97 Lisburn Road, Belfast, Northern Ireland BT9 7BL, UK

Received: 19 April 2016 Accepted: 19 February 2018

Published online: 27 February 2018

\section{References}

1. Algra AM, Rothwell PM. Effects of regular aspirin on long-term cancer incidence and metastasis: a systematic comparison of evidence from observational studies versus randomised trials. Lancet Oncol. 2012;13:518-27.

2. Cole BF, Logan RF, Halabi S, Benamouzig R, Sandler RS, Grainge MJ, et al. Aspirin for the chemoprevention of colorectal adenomas: meta-analysis of the randomized trials. J Natl Cancer Inst. 2009;101:256-66.

3. Burn J, Gerdes AM, Macrae F, Mecklin JP, Moeslein G, Olschwang S, et al. Long-term effect of aspirin on cancer risk in carriers of hereditary colorectal cancer: an analysis from the CAPP2 randomised controlled trial. Lancet. 2011;378:2081-7.

4. Rothwell PM, Wilson M, Price JF, Belch JFF, Meade TW, Mehta Z. Effect of daily aspirin on risk of cancer metastasis: a study of incident cancers during randomised controlled trials. Lancet. 2012;379:1591-601.

5. Cardwell CR, Kunzmann AT, Cantwell MM, Hughes C, Baron JA, Powe DG, et al. Low-dose aspirin use after diagnosis of colorectal cancer does not increase survival: a case-control analysis of a population-based cohort. Gastroenterology. 2014;146:700-8.
6. Kothari N, Kim R, Jorissen RN, Desai J, Tie J, Wong H-L, et al. Impact of regular aspirin use on overall and cancer-specific survival in patients with colorectal cancer harboring a PIK3CA mutation. Acta Oncol. 2015;54:487-92.

7. Goh C, Leong W, Chew M, Pan Y, Tony L, Chew L, et al. Post-operative aspirin use and colorectal cancer-specific survival in patients with stage I-III colorectal cancer. Anticancer Res. 2014:34:7407-14.

8. McCowan C, Munro AJ, Donnan PT, Steele RJC. Use of aspirin post-diagnosis in a cohort of patients with colorectal cancer and its association with all-cause and colorectal cancer specific mortality. Eur J Cancer. 2013;49:1049-57.

9. Chan AT, Ogino S, Fuchs CS. Aspirin use and survival after diagnosis of colorectal cancer. JAMA. 2009;302:649-59.

10. Bains SJ, Mahic M, Myklebust TA, Smastuen MC, Yaqub S, Dorum LM, et al. Aspirin as secondary prevention in patients with colorectal cancer: an unselected population-based study. J Clin Oncol. 2016;34:2501-8.

11. Ye X-F, Wang J, Shi W-T, He J. Relationship between aspirin use after diagnosis of colorectal cancer and patient survival: a meta-analysis of observational studies. Br J Cancer. 2014;111:2172-9.

12. Birgisson $H$, Wallin $U$, Holmberg L, Glimelius B. Survival endpoints in colorectal cancer and the effect of second primary other cancer on disease free survival. BMC Cancer. 2011;11:438. https://doi.org/10.1186/1471-2407-11-438.

13. Chubak J, Boudreau DM, Wirtz HS, McKnight B, Weiss NS. Threats to validity of nonrandomized studies of postdiagnosis exposures on cancer recurrence and survival. J Natl Cancer Inst. 2013;105:1456-62.

14. Alvarez-Madrazo S, McTaggart S, Nangle C, Nicholson E, Bennie M. Data resource profile: the Scottish national prescribing information system (PIS) Int J Epidemiol. 2016;45:714-715f.

15. WHO Collaborating Centre for Drug Statistics Methodology. Guidelines for ATC classification and DDD assignment, 2015 [Internet]. Oslo; 2014 [cited 2015 Nov 9]. Available from: https://www.whocc.no/filearchive/publications/ guidelines.pdf.

16. Lévesque LE, Hanley JA, Kezouh A, Suissa S. Problem of immortal time bias in cohort studies: example using statins for preventing progression of diabetes. BMJ. 2010;340:b5087.

17. Sundararajan V, Henderson T, Perry C, Muggivan A, Quan H, Ghali WA. New ICD-10 version of the Charlson comorbidity index predicted in-hospital mortality. J Clin Epidemiol. 2004:57:1288-94.

18. The Scottish Government. Scottish Index of Multiple Deprivation 2009: General Report [Internet]. A Scottish Government National Statistics Publication; [cited 2014 Sep 14]. Available from: http://www.gov.scot/ Publications/2009/10/28104046/0.

19. Cardwell CR, Hicks BM, Hughes C, Murray LJ. Statin use after colorecta cancer diagnosis and survival: a population-based cohort study. J Clin Oncol. 2014:32:3177-83.

20. Zhou Z, Rahme E, Abrahamowicz M, Pilote L. Survival bias associated with time-to-treatment initiation in drug effectiveness evaluation: a comparison of methods. Am J Epidemiol. 2005;162:1016-23.

21. Schisterman EF, Cole SR, Platt RW. Overadjustment bias and unnecessary adjustment in epidemiologic studies. Epidemiology. 2009;20:488-95.

22. Weinberg CR. Toward a clearer definition of confounding. Am J Epidemiol. 1993;137:1-8

23. Tamim H, Tahami Monfared AA, LeLorier J. Application of lag-time into exposure definitions to control for protopathic bias. Pharmacoepidemiol Drug Saf. 2007:16:250-8.

24. Smith A, Murphy L, Bennett K, Barron TI. Patterns of statin initiation and continuation in patients with breast or colorectal cancer, towards end-oflife. Support Care Cancer. 2017;25:1629-37.

25. Townsend N, Williams J, Bhatnagar P, Wickramasinghe K, Rayner M. Cardiovascular disease statistics, 2014. London: British Heart Foundation; 2014.

26. Baade PD, Meng X, Youl PH, Aitken JF, Dunn J, Chambers SK. The impact of body mass index and physical activity on mortality among patients with colorectal cancer in Queensland, Australia. Cancer Epidemiol Biomark Prev. 2011:20:1410-20.

27. Haydon AMM, Maclnnis RJ, English DR, Giles GG. Effect of physical activity and body size on survival after diagnosis with colorectal cancer. Gut. 2006;55:62-7

28. Kuiper JG, Phipps Al, Neuhouser ML, Chlebowski RT, Thomson CA, Irwin ML, et al. Recreational physical activity, body mass index, and survival in women with colorectal cancer. Cancer Causes Control. 2012:23:1939-48.

29. Bedson J, Whitehurst T, Lewis M, Croft P. Factors affecting over-the-counter use of aspirin in the secondary prophylaxis of cardiovascular disease. Br J Gen Pract. 2001;51:1001-3. 
30. Yang Y-X, Hennessy S, Propert K, Hwang W-T, Sarkar M, Lewis JD. Chronic statin therapy and the risk of colorectal cancer. Pharmacoepidemiol Drug Saf. 2008;17:869-76.

31. Liao X, Lochhead P, Nishihara R, Morikawa T, Kuchiba A, Yamauchi M, et al. Aspirin use, tumor PIK3CA mutation, and colorectal-cancer survival. N Engl J Med. 2012;367:1596-606.

32. Reimers MS, Bastiaannet E, Langley RE, van Eijk R, van Vlierberghe RLP, Lemmens VEP, et al. Expression of HLA class I antigen, aspirin use, and survival after a diagnosis of colon cancer. IJAMA Intern Med. 2014;174:732-9.

Submit your next manuscript to BioMed Central and we will help you at every step:

- We accept pre-submission inquiries

- Our selector tool helps you to find the most relevant journal

- We provide round the clock customer support

- Convenient online submission

- Thorough peer review

- Inclusion in PubMed and all major indexing services

- Maximum visibility for your research

Submit your manuscript at www.biomedcentral.com/submit 